\title{
Advanced High Strength Steel (AHSS) TWIP: A Door to the Future in Metal Forming
}

\author{
R.Pla-Ferrando ${ }^{1}$, S. Sánchez-Caballero ${ }^{1}$, M.J. Reig ${ }^{2}$, R. Pla ${ }^{1}$, M.A. Sellés ${ }^{2}$, \\ V.J. Segui ${ }^{2}$ \\ 'In.st. de Diseño y Fabricación, U. Politècnica de Valencia, Alcoy.E-mail:rpla@mcm.upv.es \\ ${ }^{2}$ Inst. de Tecnología de Materiales, U. Politècnica de Valencia, Alcoy.E-mail: jsegui@mom.upv.es
}

\begin{abstract}
The last decades have been characterized by a fast evolution of cars. This work shows the evolution of vehicle weight. It shows the response of car manufacturers using new materials and production methods that allow lighter velicles with lower consumption, cheaper and with lower influence on the greenhouse effect. One of the materials which means a most interesting change is the TWIP steel. This material is characterized by its high strength, his exceptional strain and excellent formability as well as lower energy consumption in their manufacture. TWIP steel are changing towards cheaper compositions and higher performance, and it's going to be great influence in the velicle weight reduction in the next years.
\end{abstract}

Keywordls: Elastic moduli, Yield stress, Plasticity, Malleability, Metals and alloys. PACS: 62.20.de, 62.20.fg, 62.20.fq, 62.20.fk, 64.70.kd.

\section{INTRODUCTION}

Cars are greatly changed in recent years. A car consist of many subsystems, one of the most important is the structure (chassis) or Body in White (BIW). The chassis is traditionally made in a set of stamped steel elements welded together to form a strong, rigid, secure and light structure.

This production process is for $99.9 \%$ of vehicles produced. Small proportion of cars, less than $0.1 \%$, are produced with aluminum, and less than $0.01 \%$ are made of carbon fiber[1].

Looking at the data of Corus Automotive, to use aluminum instead of steel for the chassis mean a partial weight reduction of $23.5 \%$ and an increase in cost of $250 \%$, in the case of the bonnet would be a reduction of $44 \%$ by weight and a $300 \%$ increase in cost. For doors, the partial reduction of weight would be $39 \%$ with a cost increase of $275 \%$.

The Boy in White is $20 \%$, other elements such as roof, doors, transmission components, brake and suspension accumulate more than $60 \%$ of the total ferrous materials, automotive, data from SMMT 2001 (AISI .) The evolution can be seen in 2005 for the Mercedes C-Class, with a decrease in ferrous materials, and an increase in plastics and wiring of control systems, as shown in Figure 1. 

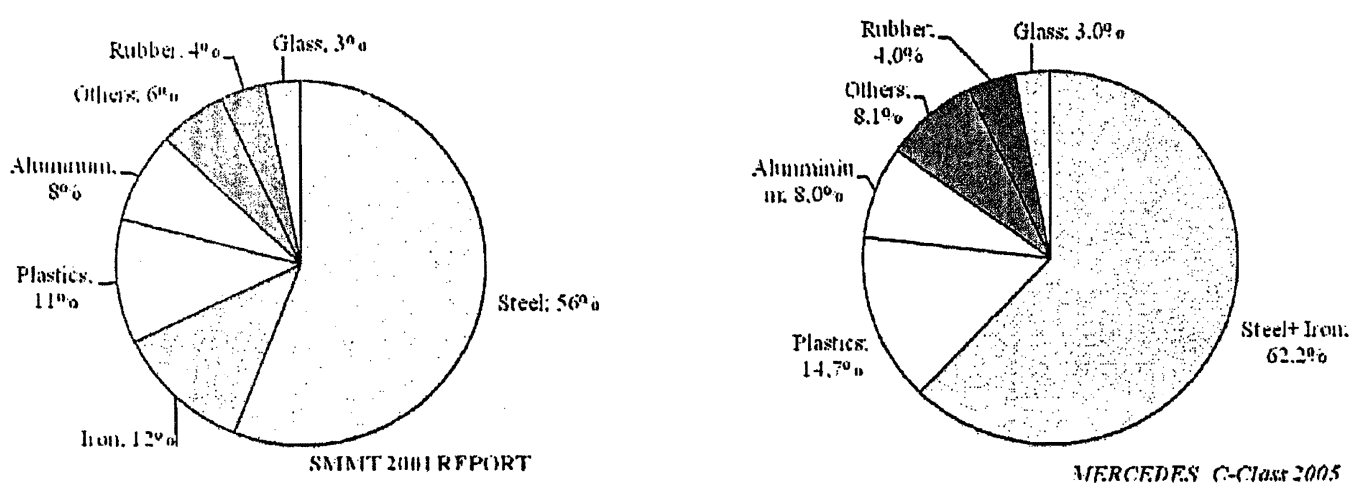

FIGURE 1. Evolution of material groups(Source: AISI $[1,2]$ )

\section{THE WEIGHT CHANGE}

If only we consider the size weight of automobiles, Figure 2 gives a rough idea of evolution:

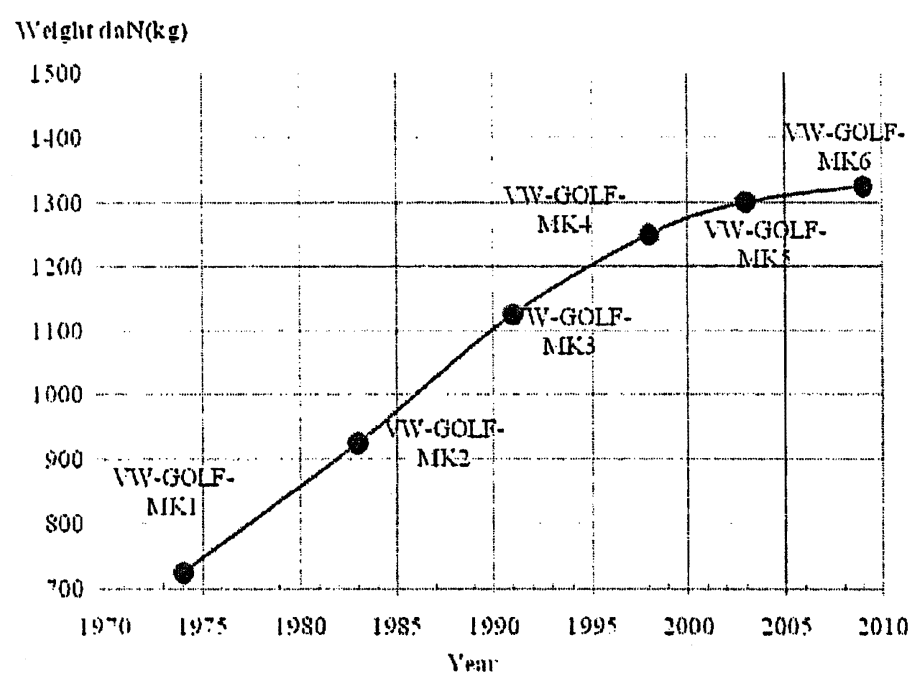

FIGURE 2. Weight evolution ( Source: VW information)

In the past 30 years, cars like the Astra, weighed about 800 daN in 1970, and reaching 1150 daN in 2002, a Volkswagen Golf has grown from an initial weight similar to the Astra, to about $13000 \mathrm{~N}$ in the same period, and about 1350daN in 2010. This evolution is explained if we consider the increased safety and comfort: air conditioning systems, control of adhesion, airbag's, onboard computer, GPS, CAN-bus and other transmission systems, electric windows, television systems and other elements and passive safety systems, adding developments such as hybrid vehicles[3]. No mention of electric vehicles, which require adding another focus.

Regardless of market laws, there are two types of regulations that influence in this rapidly changing technology. On the one hand safe standards such as Euro NCAP and the equivalent in other countries. On the other side are the increasing pressure to reduce the impact of greenhouse emissions such as the Euro 5 and Euro6 for diesel 
emissions target, the New Vehicle $130 \mathrm{~g} / \mathrm{km} \mathrm{CO} 2$ for 2012-2015 and by 2015 ELVD "95\% per vehicle mass reused / Recovered, $85 \%$ per vehicle mass reused / Recycled "[1].

The two basic ideas, first reducing greenhouse gas emissions (CO2), the decrease in fuel consumption by increasing the efficiency of various systems (engine, air conditioning, tires), weight reduction, materials and more efficient manufacturing systems, and otherwise increasing the recyclability of all the elements of the vehicle. Figure 3. shows the evolution of different national laws.

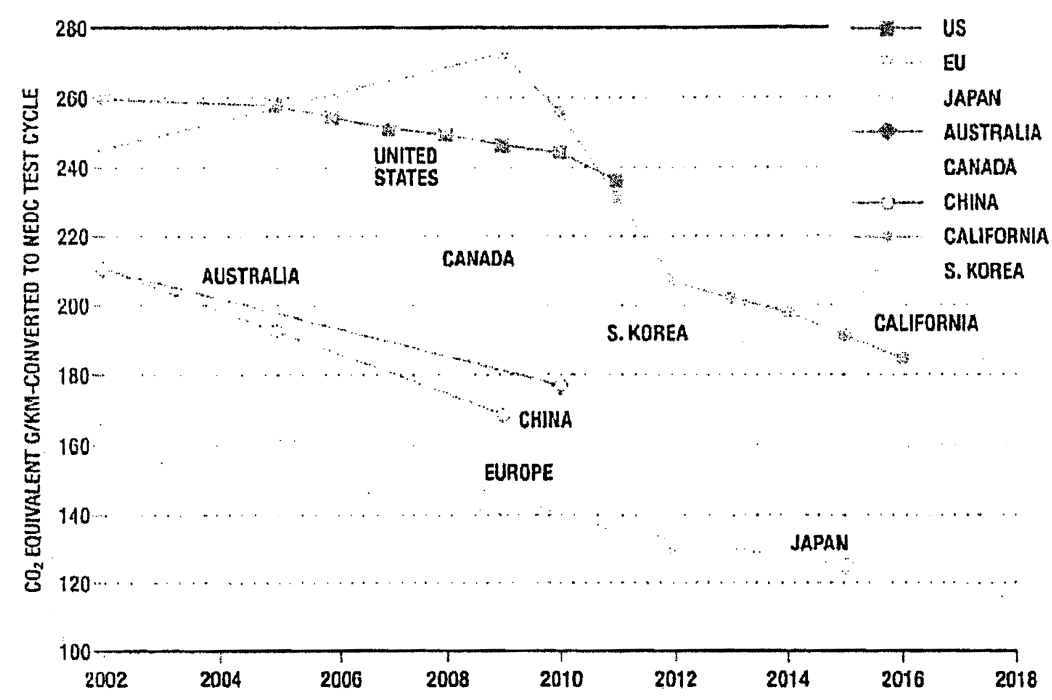

FIGURE 3. Current and projected emissions of GHG for veluicles to various countries 2002-2018. Source: ICCT[4]

Weight reduction is one of the clearest objectives. The sizing of the elements has, in general, restrictions relating to its strength, stiffness and/or absorption of energy. The idea that more resistant materials will enable lighter elements has been a key concept for engineers, as well as a cost accepted by the market, and respect for the environment is the references for the accelerated change.

Since 1998, various initiatives have led to methods for making and design of new cars, taking increasing importance of Life Cycle Assessment as a tool for decision making. Projects like ULSAB (UltraLight Steel Auto Body) [5]of AISI, have involved car manufacturers, materials producers and other participants in the process of designing, manufacturing, use and recycling of the vehicle. Results as "FSV" (Future SteelVehicle) of WorldAutoSteel[6] or "Improving and enlarging the application field of HSS and UHSS for automotive body components by the integration of Innovative Technologies based on roll forming and stretch-bending processes "[7] of the EC point the way to meeting the objectives of both the materials and manufacturing processes.

\section{THE STEELS}

We can classify the steels used in the body of a car into three groups depending on its tensile strength: Mild Steels ( $<300 \mathrm{MPa})$, Ultra High Strength Steels ( $>700 \mathrm{MPa})$ (AHSS), and High Strength Steels (HSS) between of the two previous ones[8]. 
During the last years, significant advances have been done in the second group, named advanced high strength steels (AHSS), steels designed for lighter BIW and cheaper cars. The evolution has been constant, and nowadays we can speak of a third generation of AHSS, positioned in the gap located between the first and third generation[9].

The main difference between conventional steels HSS and more advanced AHSS is its microstructure. In the HSS is a ferrite single phase, while AHSS are multiple phases, which may contain ferrite, martensite, bainite, and / or retained austenite in quantities sufficient to produce different mechanical properties. Some types of AHSS have increased hardenability and strength-ductility properties longer than conventional steels.

The manufacture of the AHSS is more complex than conventional steels. Control in manufacturing should be greater since it is based on the percentages of different phases present. Within this classification, we find the so-called Dual Phase (DP)[10], Transformation-Induced Plasticity (TRIP), Complex Phase (CP), High-strength lowalloy (HSLA) steel Ferritic-bainitic (FB), Twinning-Induced Plasticity (TWIP), HotFormed (HF) Post-Forming Heat-Treatable (PFHT).

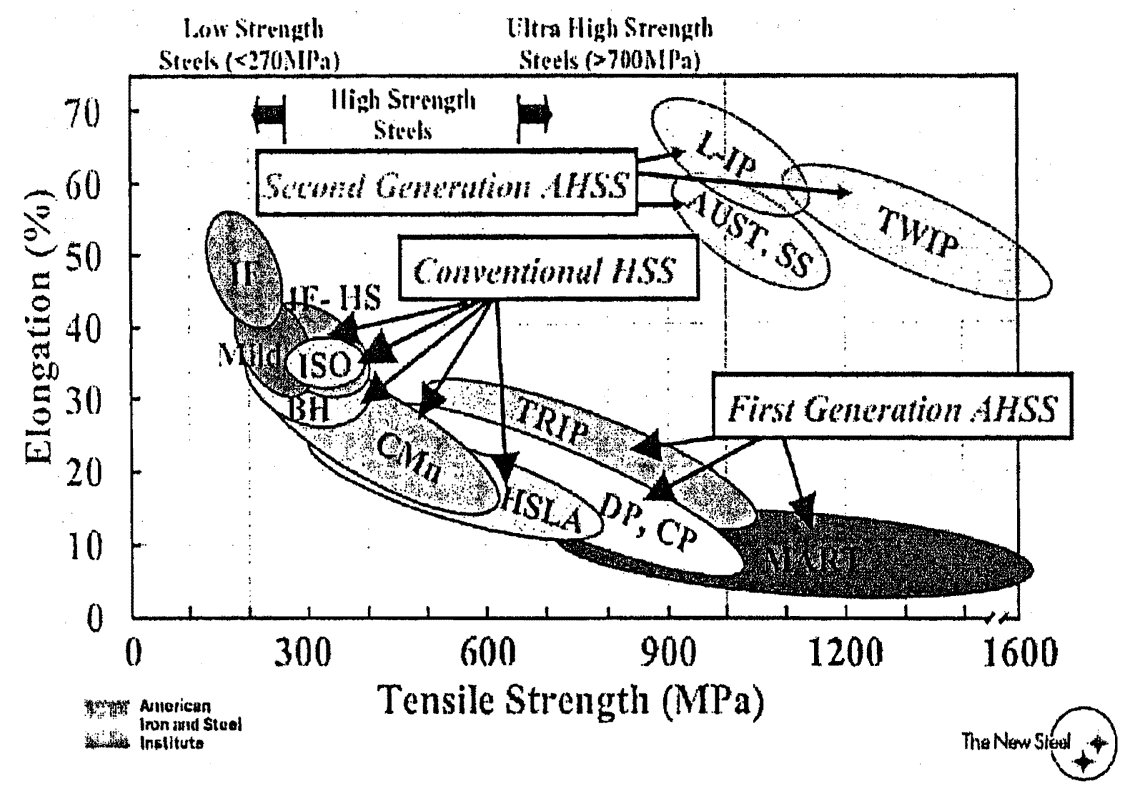

FIGURE 4. Main steels currently used. Source: AISI[8]

Figure 4 maps typical AHSS yield strength/ductility combinations and compares these to "conventional" low strength (interstitial free, IF; bake hardenable, BH; or mild steels) or high strength (carbon manganese $\mathrm{CMn}$ or high strength low alloy HSLA) sheet steels .

In Figure 4 the property band that includes DP, TRIP, CP, and MART steels (referred to as "first generation" AHSS ) incorporates other steels that also possess primarily ferritic-based microstructures. Within the band the advantageous properties of TRIP steels, i.e. higher elongations for a specific strength range, are evident. Developments continue to enhance the properties of first generation AHSS as evidenced by recent work on a new class of steels with retained austenite and 
controlled amounts of martensite produced by the quenching and partitioning process (Q\&P) and having properties superior to the MART steels. The first generation of AHSS is well established and properties and applications have been summarized in a recent IISI guidelines publication[11]. Figure 4 also shows property combinations for these steels referred to as twinning-induced plasticity (TWIP) steels or lightweight steels with induced plasticity (L-IP $\rightarrow$ ), along with the material property band for typical austenitic stainless steels. Similar materials that use shear band formation for strengthening (SIP steels) are also currently being developed. For high-production automotive applications these second generation AHSS steels are attractive due to their excellent formability. However, the steels offer processing challenges relative to low carbon sheet steels and are expensive due to the high alloy additions required to produce an austenitic microstructure. Currently there is increasing interest to develop a new class of steels, referred to as the "third generation" advanced high strength steels, [9]with anticipated properties in the intermediate band identified in Figure 4. If high strength steels could be produced with enhanced properties, e.g. tensile strength of $1000 \mathrm{MPa}$ combined with a total elongation of $30 \%$, but without the level of expensive alloy additions required in the second generation AHSS, then significant use of the these steels might be economically incorporated into advanced automotive designs.

The evolution of the design criteria and materials used can be summarized in the following table:

Table 1. Design rules change(Source [12]).

\begin{tabular}{|c|c|c|c|}
\hline Decade & Key Desgin Considerations & $\begin{array}{c}\text { Limiting } \\
\text { Performance }\end{array}$ & $\begin{array}{c}\text { Emerging Body Structure } \\
\text { Material }\end{array}$ \\
\hline 1980 & Cost, Styling, Corrosion & Stiffness & $\begin{array}{l}\text { If steel to maqke complex } \\
\text { parts, zinc coatings } \\
\text { Add: HSLA C- }\end{array}$ \\
\hline 1990 & $\begin{array}{l}\text { Cost, Scrash (door intrusion, } \\
\text { insurance repair cost reduction) }\end{array}$ & Stiffness & $\begin{array}{l}\text { Mn,BH(Martensite, recovery } \\
\text { anneal, UHS DP for bumpers } \\
\text { and door beams) }\end{array}$ \\
\hline 2000 & $\begin{array}{c}\text { Cost, Fuel Economy (weigth), } \\
\text { Ccrash (lower impulse, higher } \\
\text { energy', intrusion, car/SUV } \\
\text { comptibility', rollover) }\end{array}$ & $\begin{array}{l}\text { Crash (Energy } \\
\text { Absortion, } \\
\text { Intrusion) }\end{array}$ & 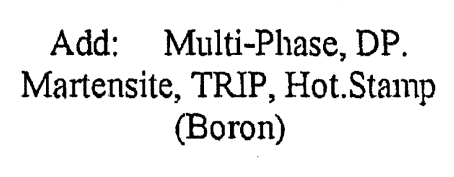 \\
\hline 2020 & $\begin{array}{l}3.5 \mathrm{mpg} \text { CAFÉ-USA } \\
120 \mathrm{~g} / \mathrm{km} \text {-Europe }\end{array}$ & $\begin{array}{l}\text { Crash (Energy } \\
\text { Absortion, } \\
\text { Intrusion) } \\
\end{array}$ & $\begin{array}{c}\text { Add: } 3^{\text {er Genn AHSS, TWIP, }} \\
\text { L-IP }\end{array}$ \\
\hline
\end{tabular}

\section{TWIP STEELS}

TWIP steels (Twinning-Induced Plasticity) have a high content of manganese (17$30 \%$ ), which determined that the steel is fully austenitic at room temperature. This makes the main mode of deformation is the twinning within the grains. The twinning causes a high value of instantaneous hardening rate ( $\mathrm{n}$ value) with a very fine microstructure. The boundaries of the resulting twins act as grain boundaries and reinforcing steel. TWIP steels combine an extremely high resistance to a very high formability. The $n$ value increases to a value of 0.4 [10]with an engineering strain of 
approx. 30\% and remains constant up to a total elongation of about $50 \%$. The tensile strength is greater than $1100 \mathrm{MPa}$, and its ability to deformation can reach $95 \%$. According to information provided by Arcelor Auto + Thyssen Krupp can reach a deformation of $35 \%$ for a resistance of $1400 \mathrm{MPa}$. TWIP steels have exceptional capacity absorb crash energy.
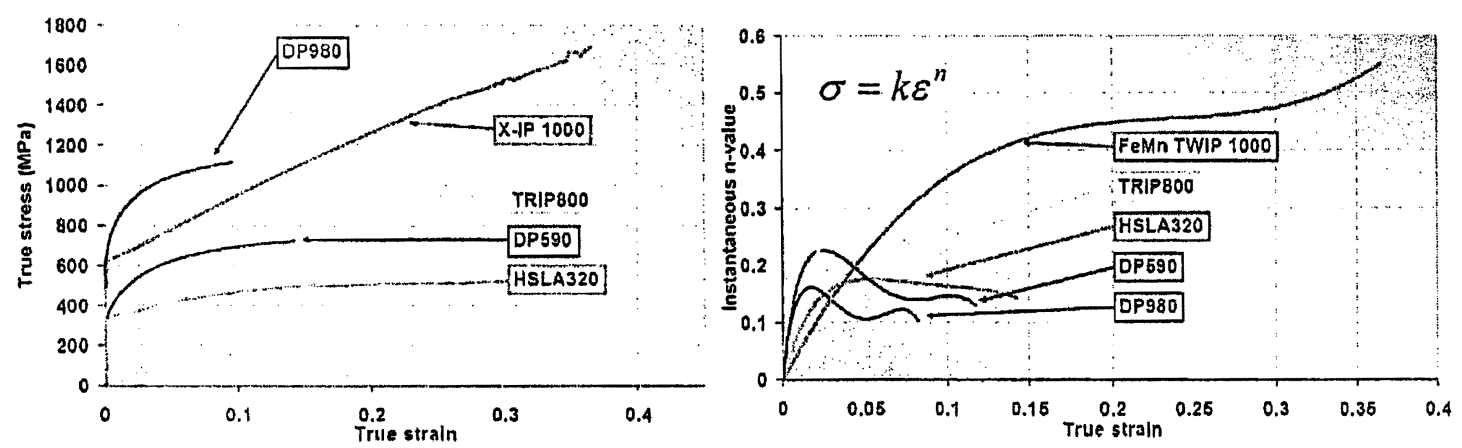

FIGURE 5. TWIP (X-IP 1000) and other AHSS Stress-Strain curves. Strain hardening exponent (n) evolution. (Source Arcelor[13]

Advances in design methodologies and manufacturing are unstoppable. A BIW today is composed of a structure of parts of different steels. Each element has a defined role, composition and structure of the steel is best fit. It is possible to find 10 different types of steel in a vehicle. AISI forecasting is to reduce the average consumption of steel per car by $8 \%$ between 2007 and 2015, reducing the use of Mild Steel in 6.5\%, and increasing the use of AHSS steels.

\section{INTEREST IN TWIP STEELS}

In the year 2000 members of Max-Planck-Institut für Eisenforschung GmbH, presented the paper entitled "High strength $\mathrm{Fe}-\mathrm{Mn}-(\mathrm{Al}, \mathrm{Si}) \mathrm{TRIP} / \mathrm{TWIP}$ steels development -properties- application "[14], and shortly before had solicited the patent "Austenitic high Manganese steel having Superior formability, strength and weldability, and manufacturing process therefor"[15]. An important number of researches have been made; the biggest steel producers and important automotive producers have reached TWIP steel patents in a short time. Now it is being investigated to reduce the cost of TWIP, and/or expand their properties making it Corrosion-Resistant[16].

The following figure shows the evolution of research and development in recent years. Also major patent holders, indicate the importance of material: Frommeyer, G; Daimler-Chrysler AG (Stuttgart, DE); THYSSENKRUPP STAHL AG (DUISBURG, $\mathrm{DE}$ ); Arcelor France; TRW Automotive GmbH; POSCO (Pohang, KR); Hyundai Motor Company (Seoul, KR); and others (Data from http://www. freepatentsonline.com) 

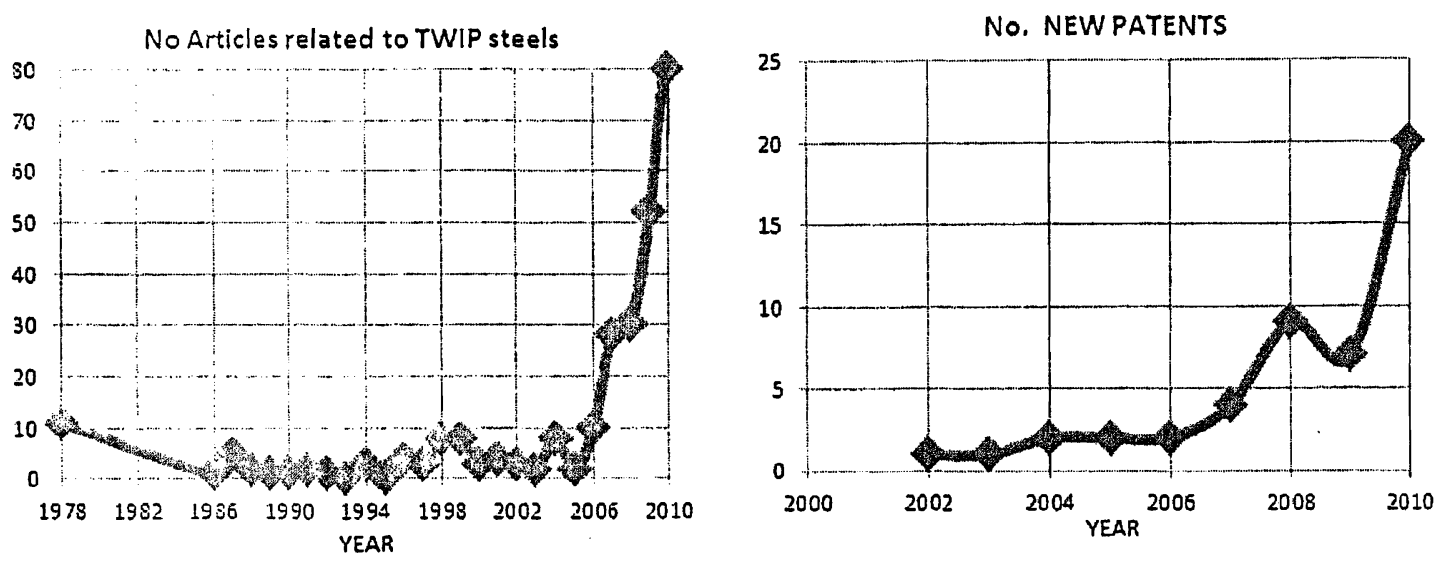

FIGURE 6. Number of patents and articles related to TWIP steels (Data from Scopus and hitp://www.frecpatentsonline.com)

\section{MECHANICAL PROPRIETIES}

Information taken of the Future Vehicle Steel Project [17]has been summarized in the following table:

Table 2. Design rules change. (From:FutureSteelVehicle Steel Technology Assessment and Design Methodology)

\begin{tabular}{lcccccccc}
\hline $\begin{array}{l}\text { Itc } \\
\mathbf{m}\end{array}$ & Steel Grade & $\begin{array}{c}\text { YS } \\
\text { (MPa) } \\
\text { Typical }\end{array}$ & $\begin{array}{c}\text { UTS } \\
\text { (MPa) } \\
\text { Min }\end{array}$ & $\begin{array}{c}\text { Tot } \\
\text { EL } \\
\text { (\%) } \\
\text { Typical }\end{array}$ & $\begin{array}{c}\text { n- } \\
\text { value } \\
\text { Typical }\end{array}$ & $\begin{array}{c}\text { Modulus } \\
\text { of } \\
\text { Elasticity } \\
\text { (MPa) }\end{array}$ & $\begin{array}{c}\text { Fatigue } \\
\text { Strength } \\
\text { Coeff } \\
\text { (MPa) }\end{array}$ & $\begin{array}{c}\text { K } \\
\text { Value } \\
\text { (MPa) }\end{array}$ \\
\hline 1 & Mild 140/270 & 150 & 270 & $38-44$ & 0.24 & $21.0 \times 104$ & 645 & 541 \\
2 & BH 280/400 & 325 & 400 & $30-34$ & 0.16 & $21.0 \times 104$ & 765 & 690 \\
3 & IF 300/420 & 320 & 420 & $29-36$ & 0.20 & $21.0 \times 104$ & 775 & 759 \\
4 & FB 450/600 & 530 & 560 & $18-23$ & 0.11 & $21.0 \times 104$ & 950 & 921 \\
5 & SF 570/640 & 600 & 640 & $20-24$ & 0.08 & $21.0 \times 104$ & 1005 & 989 \\
6 & HSLA 550/650 & 585 & 650 & $19-23$ & 0.12 & $21.0 \times 104$ & 1020 & 1009 \\
7 & SF 600/780 & 650 & 780 & $20-24$ & 0.07 & $21.0 \times 104$ & 1175 & 1201 \\
8 & DP 500/800 & 520 & 800 & $14-20$ & 0.14 & $21.0 \times 104$ & 1180 & 1303 \\
9 & TRIP 450/800 & 550 & 800 & $26-32$ & 0.24 & $21.0 \times 104$ & 1170 & 1690 \\
10 & TRIP 600/980 & 650 & 980 & $15-17$ & 0.13 & $21.0 \times 104$ & 1335 & 1301 \\
11 & TWI 500/980 & $\mathbf{5 5 0}$ & $\mathbf{9 8 0}$ & $\mathbf{5 0 - 6 0}$ & 0.40 & $\mathbf{2 1 . 0 \times 1 0 4}$ & $\mathbf{1 3 3 5}$ & $\mathbf{1 4 0 1}$ \\
12 & CP 1000/1200 & 1020 & 1200 & $8-10$ & 0.10 & $21.0 \times 104$ & 1575 & 1700 \\
13 & DP1150/1270 & 1160 & 1270 & $8-10$ & 0.12 & $21.0 \times 104$ & 1620 & 1751 \\
14 & MS 1150/1400 & 1200 & 1400 & $4-7$ & 0.07 & $21.0 \times 104$ & 1765 & 1937 \\
15 & CP 1050/1470 & 1060 & 1470 & $7-9$ & 0.04 & $21.0 \times 104$ & 1840 & 2030 \\
16 & MS 1250/1500 & 1265 & 1500 & $3-6$ & 0.07 & $21.0 \times 104$ & 645 & 541 \\
\hline
\end{tabular}

The Steels TWIP differ from others from the same level of resistance for your high capacity of plastic deformation. This characteristic makes them very adapted for elements that have to absorb impact loads, feature of great importance in crash boxes. 


\section{FORMABILITY OF TWIP STEELS}

They have been compared the characteristics of common steels in the construction of automobiles, through the Forming Limit Diagram FLD [18, 19].Analysis of clustered diagrams is notes that the formability of the two TWIP'S (X-IP1000 and TWIP 940) is-higher to the other materials, thus confirming the expectations generated at the diagrams and dates shown in the preceding paragraphs

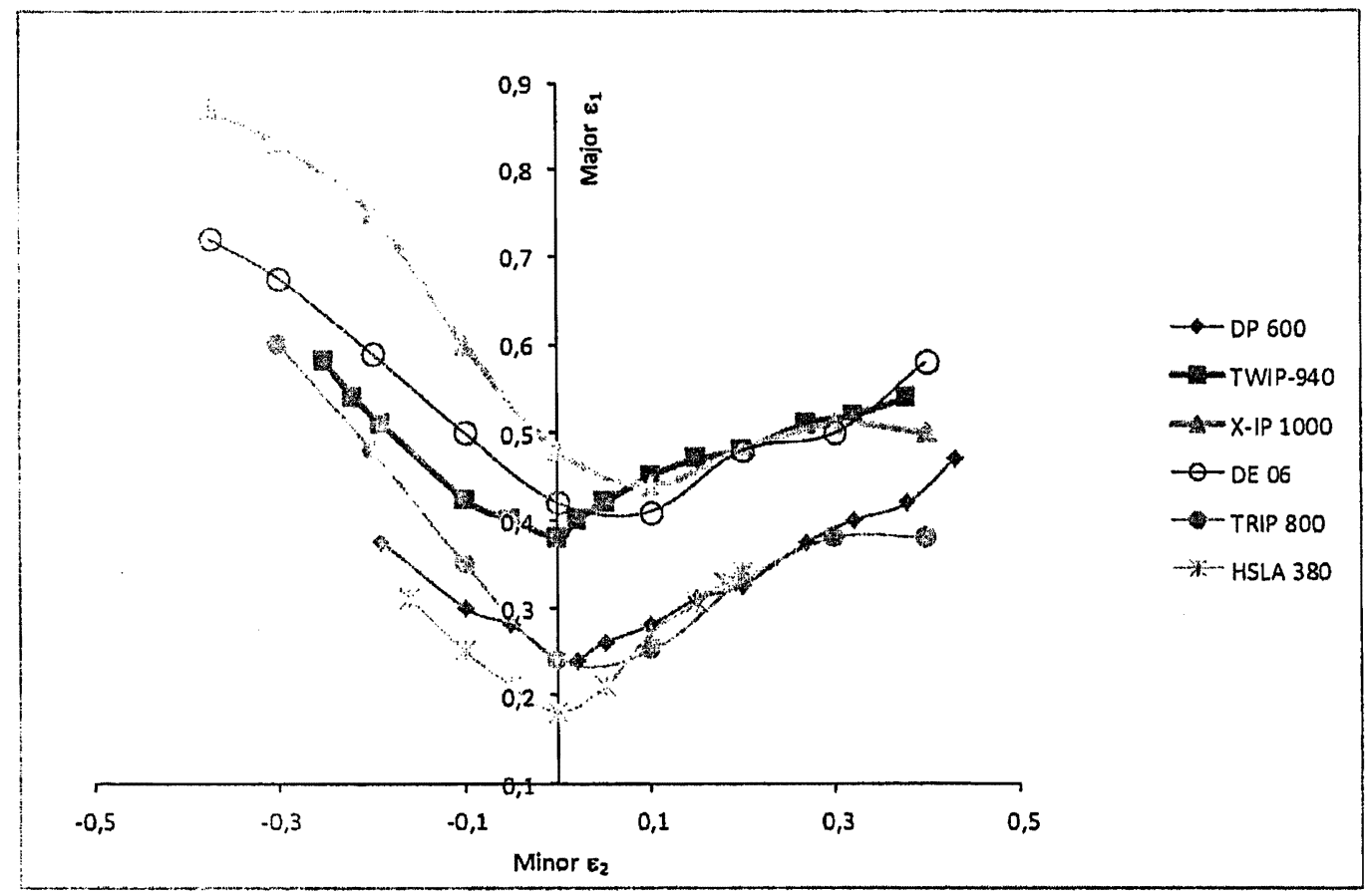

Figure 7. FLD diagrams of TWIP steels compared to other steel tips(Source:Arcelor)

\section{CONCLUSION}

Approximately $60 \%$ of the weight of the vehicle is of steel. Cars weight has grown last decades and the regulations force to reduce the greenhouse gas emission as well as the recyclability of the cars. The TWIP steels present characteristics as for resistance, capacity of deformation and formability do them candidates for collaborating in the manufacture of the lighter vehicles. In this moment TWIP steels are on the market, and are being used in new car design codes. Given its excellent mechanical characteristics, is likely to spread to other areas of mechanical engineering

\section{REFERENCES}

1. C. AUTOMOTIVE, "POCKET BOOK OF STEEL," CORUS AUTOMOTIVE, 2009.

2. H. Ding, et al., "Strain hardening behavior of a TRIP/TWIP steel with $18.8 \% \mathrm{Mn}$," Materials Science and Engineering: $A$, vol. 528, pp. 868-873, 2011. 
3. J. D. Mol, et al., "The evolution of car power, weight and top speed during the last twenty years in Belgium : a consideration for future policies," ed. Brussels, Belgium VUB Press 2009, pp. 607620.

4. ICCT. (2007). Passenger Vehicle Greenhouse Gas and Fuel Economy Standards: A Global Upclate. Available: http://www.theicct.org/pubs/PV_standards_2007.pdf

5. WorldAutoSteel. (1998). UltraLight Steel Auto Body (ULSAB) Programme. Available: http://www.worldautosteel.org/projects/ULSAB.aspx

6. AutoSteel, "Future Steel Velicle Project," http://www.worldautosteel.org/Projects/Future-SteelVehicle/Phase-I-Results-Phase-2-Launch.aspx, 2010.

7. L. Rizzo, et al., "Improving and enlarging the application field of HSS and UHSS for automotive body' components by the integration of innovative technologies based on rollforming and stretchbending processes," European Commission-Research Fund for Coal and Steel, 2010.

8. AISI. (2008). Application and Repairability of Advanced High-Strength Steels. Available: hltp://w'w'w.stcel.org/ /media/Files/Autosteel/Researcl/Safety/2008_ICAR_PowerPoint_Print_Ve rsion.ashx

9. D. K. Matlock and J. G. Speer, "Third Generation of AHSS: Microstructure Design Concepts," ed, 2009, pp. 185-205.

10. AIMME-OTEA(Valencia), "ESTUDIO DEL EMPLEO DE NUEVOS MATERIALES PARA LAS APLICACIONES TRADICIONALES DE LOS FABRICADOS METÁLICOS," INFORME, MAYO 20092009.

11. WorldAutoSteel, "Advanced High Strength Steel (AHSS) Aplication Gidelines," 2008.

12. D. Anderson, "Application and Repairability of Advanced High-Strength Steels," American an Irons Steel Institute, 2008.

13. P. Cugy, et al., "A Super-High Strength FE-MN-C Austenitic Steel with Excellent Formability for Automolive Applications," University of Cambridge Department of Materials Science \& Metallirgy, 2005.

14. O. Grässel, et al., "High strength Fe-Mn-(Al, Si) TRIP/TWIP steels development -- properties -application," International Journal of Plasticity, vol. 16, pp. 1391-1409, 2000.

15. G. E. Frommeyer, DE), Graissel,Oliver (4700 Krefeld, DE), "Light constructional steel and the use thereof," United States Patent, 2002.

16. C. Scolt, et al,, "The development of a new Fe-Mn-C austenitic steel for automotive applications," Rev'ue de Metallurgie. Cahiers D'Informations Techniques, vol. 103, pp. 293-302, 2006.

17. WorldAutoSteel, "FutureSteelVehicle Steel Technology Assessment and Design Methodology Interim Report - 30 June 2010," Report, 2010.

18. K. Chung, et al., "Formability of TWIP (twinning induced plasticity) automotive sheets," International Joumal of Plasticity, vol, 27, pp. 52-81, 2011.

19. D. Cornetle, et al., "Ultra high strength FeMn TWIP steels for automotive safety parts," Aciers d̀ très haute résistance FeMfn TWIP pour pièces de sécurité dans la construction automobile, vol. 102, pp. 905-918+iv, 2005. 